\title{
Adubação nitrogenada no feijoeiro comum irrigado em diferentes épocas, com e sem parcelamento das doses
}

\author{
Danilo Pereira Ramos \\ Sérgio Alves de Sousa \\ Taynar Coelho de Oliveira \\ Gustavo de Melo Oliveira Gonçalves \\ Nathan Gonçalves dos Passos \\ Rodrigo Ribeiro Fidelis * \\ Universidade Federal do Tocantins, Campus de Gurupi \\ Rua Badejós, Chác. 69/72, Lt. 07, Zona Rural, Caixa Postal 66, CEP 77402-970, Gurupi $\square$ TO, Brasil \\ * Autor para correspondência \\ fidelisrr@uft.edu.br
}

Submetido em 20/05/2013

Aceito para publicação em 10/12/2013

\section{Resumo}

O objetivo deste artigo é avaliar o efeito da adubação nitrogenada em diferentes épocas nas características agronômicas de cultivares de feijão comum, no período da entressafra. Foi instalado um experimento no município de Gurupi-TO, com blocos ao acaso, sob esquema fatorial $3 \times 5$, constituído por três cultivares e cinco épocas de aplicação de nitrogênio, com quatro repetições. Foram avaliados os cultivares IAC Alvorada, IPR Juriti e BRS Requinte. Quanto à adubação nitrogenada, foram avaliadas 5 épocas, sendo a primeira correspondente a testemunha $\left(\mathrm{E}_{1}=\right.$ zero de $\left.\mathrm{N}\right)$ e as demais com a aplicação de $100 \mathrm{~kg} \cdot \mathrm{ha}^{-1} \mathrm{de} \mathrm{N}$, utilizando-se ureia como fonte, da seguinte forma: $\mathrm{E}_{2}=100 \%$ de $\mathrm{N}$ aplicado na semeadura; $\mathrm{E}_{3}=100 \%$ de $\mathrm{N}$ aplicado aos 25 dias após a emergência (DAE); $\mathrm{E}_{4}=50 \%$ de $\mathrm{N}$ aplicado 20 DAE e 50\% 30 DAE; $\mathrm{E}_{5}=33 \%$ de $\mathrm{N}$ aplicado $15 \mathrm{DAE}, 33 \% 25 \mathrm{DAE}$ e $33 \% 35$ DAE. Existiu variabilidade genética entre os cultivares quanto à resposta, bem como diferenças entre as épocas de adubação nitrogenada. Os cultivares IAC Alvorada e IPR Juriti obtiveram maior produtividade de grãos. A época de aplicação de nitrogênio parcelada em 15, 25 e 35 DAE proporcionou maior produtividade de grãos para os cultivares IAC Alvorada e IPR Juriti.

Palavras-chave: Cultivares de feijão; Parcelamento de nitrogênio; Phaseolus vulgaris L.; Produtividade de grãos; Teor de nitrogênio foliar

\section{Abstract}

Nitrogen fertilization in irrigated common bean at different times, with and without dose division. This article aims to evaluate the effect of nitrogen fertilization at different times on the agronomic characteristics of common bean cultivars, within the intercrop period. An experiment was installed in the town of Gurupi, Tocantins, Brazil, with randomized blocks, under a 3 x 5 factorial scheme, consisting of 3 cultivars and 5 nitrogen application times, with 4 repetitions. We evaluated the cultivars IAC Alvorada, IPR Juriti, and BRS 
Requinte. Regarding nitrogen fertilization, we evaluated 5 times, the first corresponding to control $\left(\mathrm{E}_{1}=\mathrm{N}\right.$ zero $)$ and the others applying $100 \mathrm{~kg} \cdot \mathrm{ha}^{-1}$ of nitrogen, using urea as their source, as follows: $\mathrm{E}_{2}=100 \%$ of N applied at sowing; $\mathrm{E}_{3}=100 \%$ of $\mathrm{N}$ applied 25 days after emergence (DAE); $\mathrm{E}_{4}=50 \%$ of $\mathrm{N}$ applied $20 \mathrm{DAE}$ and $50 \% 30$ $\mathrm{DAE} ; \mathrm{E}_{5}=33 \%$ of $\mathrm{N}$ applied $15 \mathrm{DAE}, 33 \% 25 \mathrm{DAE}$, and 33\% 35 DAE. There was genetic variability among cultivars with regard to response, as well as differences between nitrogen fertilization times. The cultivars $I A C$ Alvorad $a$ and IPR Juriti obtained higher grain yields. The nitrogen application time divided into 15, 25 and 35 DAE enabled a higher grain yield for the cultivars IAC Alvorada and IPR Juriti.

Key words: Bean cultivars; Grain yield; Leaf nitrogen content; Nitrogen division; Phaseolus vulgaris L.

\section{Introdução}

Cultivado em aproximadamente 100 países, o feijoeiro comum (Phaseolus vulgaris L.) é a espécie do gênero Phaseolus mais explorada, constituindo aproximadamente $95 \%$ da produção mundial (DIDONET, 2005; SANTOS; GAVILANES, 2006). Apresenta grande papel social, devido à grande geração de emprego e, também, por ser constituinte da dieta do brasileiro, sendo, muitas vezes, a principal fonte de proteína para diversas famílias de baixo poder aquisitivo, além de fornecer vitaminas, fibras, ferro, fósforo, magnésio, cálcio e zinco (BROUGHTON et al., 2003).

Segundo estimativas da CONAB (2013), a produtividade média nacional e do estado do Tocantins é $895 \mathrm{~kg} . \mathrm{ha}^{-1}$ e $1.410 \mathrm{~kg} . \mathrm{ha}^{-1}$, respectivamente. No entanto o feijoeiro comum tem potencial para ser cultivado no sul do estado do Tocantins no período da entressafra com irrigação suplementar, sendo confirmado por alguns estudos realizados, com produtividades superiores a $3.000 \mathrm{~kg} \cdot \mathrm{ha}^{-1}$ (SALGADO et al., 2011; 2012). Entretanto, ainda são poucos os estudos realizados nesse ambiente e região, principalmente relacionados à adubação nitrogenada, que possam servir de subsídios para futuros programas de melhoramento e para agricultura local (SALGADO et al., 2012).

Embora a associação com bactérias do gênero Rhizobium atenda parte da exigência do feijoeiro por nitrogênio $(\mathrm{N})$, normalmente há necessidade de complementação com adubação mineral, pois, a quantidade fornecida por esse processo geralmente não é suficiente (BINOTTI et al., 2007). O nitrogênio é o nutriente absorvido em quantidades mais elevadas pelo feijoeiro (VIEIRA, 2006; SODEK, 2008), sendo responsável pelo aumento da área foliar, que aumenta a eficiência de intercepção da radiação solar e a taxa fotossintética e, consequentemente, o crescimento, o desenvolvimento e a produtividade de grãos da planta (LOPES et al., 2004; FAGERIA; BALIGAR, 2005).

Para proporcionar adequada nutrição da planta, o fornecimento de $\mathrm{N}$ deve ser realizado na época em que ainda é possível aumentar o número de vagens por planta, isto é, antes do florescimento (ROSOLEM, 1996). Ambrosano et al. (1996) constataram que a aplicação de nitrogênio deve ser feita dos 15 aos 45 DAE, além de ser parcelada quando da utilização de doses elevadas. Aidar e Kluthcouski (2009) concluíram em seus trabalhos que a aplicação de todo $\mathrm{N}$, imediatamente antes da semeadura, é a prática mais indicada para cultura, tanto em sistema de plantio direto como no manejo convencional do solo.

Devido às suas transformações microbiológicas no solo, o $\mathrm{N}$ se perde facilmente por diversos processos como lixiviação, volatilização e desnitrificação, fazendo com que a carência na planta seja limitante à produtividade de grãos, podendo ainda se tornar poluente ambiental (FAGERIA; BALIGAR, 2005; SANT'ANA et al., 2010). Dessa forma, o uso racional da adubação nitrogenada é fundamental para obtenção da máxima eficiência dos fertilizantes e altas produtividades, com redução no custo de produção e os riscos de poluição ambiental (CARDOSO et al., 2011).

São escassos os trabalhos com a cultura do feijão comum que demonstram a viabilidade do parcelamento da adubação nitrogenada na época da entressafra em condições de Cerrado do estado do Tocantins, de modo a proporcionar aumento na eficiência de uso do fertilizante e na produtividade de grãos do feijoeiro.

Diante deste contexto, objetivou-se com este trabalho avaliar o efeito da adubação nitrogenada realizada em diferentes épocas nas características 
agronômicas de cultivares de feijão comum, no período da entressafra, na região sul do estado do Tocantins.

\section{Material e Métodos}

O experimento foi conduzido em campo, na estação experimental da Universidade Federal do Tocantins, Campus Universitário de Gurupi, localizado a 11 ${ }^{\circ} 43$ ' $45^{\prime}$ " de latitude sul, 49 $04^{\prime} 07^{\prime \prime}$ de longitude oeste e altitude de $278 \mathrm{~m}$, na entressafra de 2012. O solo é classificado, de acordo com EMBRAPA (2006), como Latossolo Vermelho - Amarelo distrófico. A caracterização climática local é $A w$ Cerrado ou Savana tropical, do tipo mesotérmico com chuvas de verão e inverno seco segundo Koppen - Geiger (PEEL et al., 2007).

$\mathrm{Na}$ área onde o experimento foi implantado há um histórico de utilização com rotação de cultura, arroz na safra e feijão comum na entressafra. No ano de 2009, foi realizada calagem com 3 th.ha ${ }^{-1}$ de calcário dolomítico $($ PRNT $=90 \%)$ para a correção do solo. Antes da instalação do experimento foram coletadas amostras de solo da camada de 0-20 cm para a caracterização dos atributos químicos e físicos, com os seguintes resultados: $\mathrm{pH}$ em $\mathrm{CaCl}_{2}=5,3 ;$ M.O $(\%)=1,1 ; \mathrm{P}(\mathrm{Mel})=9,9$ mg.dm ${ }^{-3} ; \mathrm{K}=0,08 \mathrm{cmol}_{\mathrm{c}} \cdot \mathrm{dm}^{-3} ; \mathrm{Ca}=0,8 \mathrm{cmol} \cdot \mathrm{dm}^{-3} ; \mathrm{Mg}$ $=0,6 \mathrm{cmol} \cdot \mathrm{dm}^{-3} ; \mathrm{Ca}+\mathrm{Mg}=1,4 \mathrm{cmol} \cdot \mathrm{dm}^{-3} ; \mathrm{H}+\mathrm{Al}=0,23$ cmol.dm ${ }^{-3} ; \mathrm{Al}=0,0 \mathrm{cmol} . \mathrm{dm}^{-3} ; \mathrm{SB}=1,5 \mathrm{cmol} . \mathrm{dm}^{-3} ; \mathrm{V}=$ $88,2 \% ; 735,2$ g.kg-1 de areia; 57,2 g. kg $^{-1}$ de silte e 207,6 g. $\mathrm{kg}^{-1} \mathrm{de}$ argila.

$\mathrm{O}$ experimento foi conduzido em blocos ao acaso, em esquema fatorial $3 \times 5$, constituído por três cultivares e cinco épocas de aplicação de nitrogênio, com quatro repetições. Cada unidade experimental foi constituída por quatro linhas de 4,0 m de comprimento, espaçadas $0,45 \mathrm{~m}$ entre si. Como área útil foi utilizada duas linhas centrais, desprezando-se 0,50 $\mathrm{m}$ em ambas as extremidades.

O preparo do solo foi realizado de forma convencional, com uma aração e duas gradagens. Para realização do estudo, foram utilizadas três cultivares feijão comum do grupo carioca, IAC Alvorada, IPR Juriti e BRS Requinte. A semeadura foi realizada no dia 2 de junho de 2012, visando à obtenção de estande final de 12 plantas por metro.
Foi realizado o tratamento de sementes com fungicida pertencente aos grupos químicos benzimidazol e dimetilditiocarbamato $\left(45+105\right.$ g i.a. $100 \mathrm{~kg}^{-1} \mathrm{de}$ sementes) e inseticidas pertencentes aos grupos químicos neonicotinoides (105 g i.a. $100 \mathrm{~kg}^{-1}$ de sementes) e piretroide e antranilamida $\left(10+20 \mathrm{~g}\right.$ i.a. $100 \mathrm{~kg}^{-1}$ de sementes). Durante a condução do experimento, a área foi mantida limpa de plantas daninhas com a aplicação de herbicidas pertencentes aos grupos químicos ariloxifenoxipropiônico (75 g i.a. ha-1) e benzotiadiazinona ( $\left.720 \mathrm{~g}^{\text {i.a. }} \mathrm{ha}^{-1}\right)$, além de capina manual antes do florescimento (R6). Para o controle dos insetos foram aplicados os inseticidas dos grupos químicos piretroide + antranilamida $\left(10+20\right.$ g i.a. ha $\left.{ }^{-1}\right)$, neonicotinoide $\left(50+\mathrm{g}\right.$ i.a. $\left.\mathrm{ha}^{-1}\right)$ e metilcarbamato de oxima (172 g i.a. ha ${ }^{-1}$ ). Os demais tratos culturais e fitossanitários empregados foram os recomendados para cultura do feijoeiro (VIEIRA et al., 2006).

A irrigação foi realizada de acordo com as necessidades da cultura e seguindo recomendação para Santo Antônio de Goiás - GO (CURI; CAMPELO JÚNIOR, 2001). Utilizou-se sistema por aspersão convencional com turno de rega de dois dias, tendo um período de funcionamento de duas horas. A vazão dos aspersores utilizados com pressão na base de $20 \mathrm{mca}$ propiciou lâmina d'água de $5,2 \mathrm{~mm} \cdot \mathrm{h}^{-1}$.

A adubação básica de semeadura foi realizada com base na análise de solo e nas recomendações para a cultura, aplicando-se, no sulco de plantio 460 kg.ha-1 do formulado NPK 00-25-15, de forma a fornecer 115 kg.ha-1 de $\mathrm{P}_{2} \mathrm{O}_{5}$ e $69 \mathrm{~kg} \cdot \mathrm{ha}^{-1}$ de $\mathrm{K}_{2} \mathrm{O}$.

Com relação à adubação nitrogenada, foram avaliadas cinco épocas, sendo a primeira correspondente a testemunha com zero de $\mathrm{N}\left(\mathrm{E}_{1}=\right.$ zero de $\left.\mathrm{N}\right)$ e, nas demais, aplicados $100 \mathrm{~kg} \cdot \mathrm{ha}^{-1}$ de N, utilizando-se ureia como fonte, da seguinte forma: $\mathrm{E}_{2}=100 \%$ de $\mathrm{N}$ aplicado na semeadura; $\mathrm{E}_{3}=100 \%$ de $\mathrm{N}$ aplicado aos 25 dias após a emergência (DAE); $E_{4}=50 \%$ de $\mathrm{N}$ aplicado aos 20 e $50 \%$ aos 30 DAE; $\mathrm{E}_{5}=33 \%$ de $\mathrm{N}$ aplicado aos $15,33 \%$ aos 25 e $33 \%$ aos 35 DAE. O florescimento pleno da cultura ocorreu 44 DAE e o ciclo teve a duração de 90 dias em todos os tratamentos. 
Para verificar o desempenho dos cultivares de feijão comum em função das diferentes épocas de adubação nitrogenada, avaliou-se a massa de matéria seca da parte aérea: por ocasião do florescimento (44 DAE), foram coletadas cinco plantas por parcela e secando-as em estufa de circulação forçada com temperatura média de $60-70^{\circ} \mathrm{C}$, até atingir massa constante; teor de nitrogênio nas folhas: por ocasião do florescimento pleno foram coletados, na área útil de cada parcela, o terceiro trifólio de 10 plantas que posteriormente foram submetidos à secagem em estufa de ventilação forçada à temperatura média de $60-70^{\circ} \mathrm{C}$ até atingir massa constante. As folhas coletadas foram moídas em moinho tipo Wiley para determinação dos teores de $\mathrm{N}$, conforme metodologia descrita por Malavolta et al. (1997).

Para quantificação das características fitotécnicas, amostraram-se cinco plantas aleatórias e representativas na área útil de cada parcela donde se avaliou altura da planta: medindo-se o colo da planta até o final da haste principal; altura de inserção de primeira vagem: medindo-se do solo até o ponto de inserção da primeira vagem; diâmetro do caule: medindo-se do colo da planta com paquímetro digital; número de vagens por planta: sendo obtido pela contagem do número total de vagens por planta; número de grãos por vagem: obtido por meio do número total de grãos e dividindo o resultado pelo número total de vagens; massa de cem grãos: tomando-se cem grãos da área útil, pesando e corrigindo a umidade para $13 \%$ e; produtividade de grãos: feito por meio da massa de grãos da área útil em quilogramas, com correção para $13 \%$ de umidade transformando os dados para kg.ha-1.

Os dados experimentais foram submetidos à análise de variância e aplicação do teste F. Para as comparações entre as médias dos tratamentos, foi utilizado o teste de Tukey a $5 \%$ de probabilidade. Utilizou-se, para tais análises, o programa computacional SISVAR (FERREIRA, 2011).

\section{Resultados e Discussão}

Analisando os dados das Tabelas 1 e 2, observa-se significância da interação para as características massa de matéria seca da parte aérea, inserção da primeira vagem, diâmetro do caule e produtividade de grãos, mostrando que o fator época de aplicação de nitrogênio influenciou de forma diferenciada nos cultivares avaliados, sendo, portanto, realizado o desdobramento de um fator dentro do outro. Para as características teor de nitrogênio foliar, altura de planta, número de vagens por planta, número de grãos por vagem e massa de cem grãos, não foi observado significância da interação, evidenciando que os fatores são independentes, ou seja, os cultivares não são influenciados de forma diferente pelas épocas de aplicação de nitrogênio, sendo, portando, estudados isoladamente. Observou-se ainda significância de todas as características excetuando teor de nitrogênio foliar e produtividade de grãos para o fator cultivar, evidenciando variabilidade genética entre os genótipos avaliados. Para o fator época de aplicação de nitrogênio, observou-se significância das características diâmetro do caule, número de vagem por planta e número de grãos por vagem, evidenciando diferença entres os tratamentos aplicados.

Os elevados coeficientes de variação para as variáveis produtividade de grãos $(23,95 \%)$ e massa de matéria seca da parte aérea $(25,68 \%)$, não são, necessariamente, consideradas inadequados (acima de $20 \%$ sob condições ideais) para ensaios de condições de estresse (BLUM, 1988).

Para a característica massa de matéria seca da parte aérea (Tabela 3), pode se observar que não houve diferença significativa entre os cultivares avaliados quando se aplicou nitrogênio independente de ser em dose única ou parcelada. Entretanto, quando não se aplicou N, foi observada superioridade do IPR Juriti apesar de não diferir significativamente do IAC Alvorada. Não houve diferença significativa entre as épocas de aplicação de nitrogênio para todos os cultivares.

Resultados semelhantes foram obtidos por Soratto et al. (2006) onde a massa seca da parte aérea do feijoeiro não foi influenciada pela aplicação de $\mathrm{N}$ em cobertura, tão pouco pela forma de parcelamento, contrastando com os resultados obtidos por Binotti et al. (2007) que observaram menores massas de matéria seca da parte aérea do feijoeiro na testemunha, ao trabalhar com oito épocas de adubação nitrogenada em três safras consecutivas. 
TABELA 1: Resumo da análise de variância das características massa de matéria seca da parte aérea (MS), teor de nitrogênio foliar (TNF), altura de planta (AP), inserção da primeira vagem (IPV) e diâmetro do caule (DC), de três cultivares de feijão comum cultivadas em ambientes com diferentes épocas de adubação nitrogenada. Gurupi $\square$ Tocantins, 2012.

\begin{tabular}{lcccccc}
\hline \multirow{2}{*}{$\begin{array}{c}\text { Fonte de } \\
\text { variação }\end{array}$} & GL & MS & TNF & AP & IPV & DC \\
\cline { 2 - 7 } & Repetição & 6,35 & 17,36 & 257,52 & 1,06 & 0,91 \\
Cultivar (C) & 2 & $47,24^{* *}$ & $0,10^{\text {ns }}$ & $3609,75^{* *}$ & $112,24^{* *}$ & $7,41^{* *}$ \\
Época (E) & 4 & $16,53^{\text {ns }}$ & $0,11^{\text {ns }}$ & $99,32^{\text {ns }}$ & $4,86^{\text {ns }}$ & $1,22^{* *}$ \\
C x E & 8 & $16,89^{*}$ & $0,44^{\text {ns }}$ & $127,88^{\text {ns }}$ & $9,73^{* *}$ & $0,54^{*}$ \\
Resíduo & 42 & 7,39 & 0,21 & 121,20 & 2,29 & 0,20 \\
\hline Média & & 10,59 & 3,34 & 67,64 & 18,36 & 5,30 \\
CV (\%) & & 25,68 & 13,87 & 16,28 & 8,24 & 8,59 \\
\hline
\end{tabular}

${ }^{\text {ns }}$ não significativo; ${ }^{* *}$ significativo para $\mathrm{P} \leq 0,01 ;{ }^{*}$ Significativo para $\mathrm{P} \leq 0,05$ pelo teste $\mathrm{F}$.

TABELA 2: Resumo da análise de variância das características número de vagens por planta (NVP), número de grãos por vagens (NGV), massa de 100 grãos (M100) e produtividade de grãos (PG), de três cultivares de feijão comum cultivadas em ambientes com diferentes épocas de adubação nitrogenada. Gurupi - Tocantins, 2012.

\begin{tabular}{lccccc}
\hline \multirow{2}{*}{ Fonte de variação } & GL & NVP & NGV & M100 & PG \\
\cline { 2 - 5 } & 3 & 29,08 & 0,30 & 12,12 & 222598,31 \\
Repetição & 2 & $187,64^{* *}$ & $17,60^{* *}$ & $474,84^{* *}$ & $147897,28^{\text {ns }}$ \\
Cultivar (C) & $18,16^{*}$ & $0,76^{*}$ & $2,12^{\text {ns }}$ & $298890,44^{\text {ns }}$ \\
Época (E) & 4 & $12,99^{\text {ns }}$ & $0,50^{\text {ns }}$ & $6,88^{\text {ns }}$ & $427144,72^{* *}$ \\
C x E & 8 & 0,24 & 3,24 & 128238,68 \\
Resíduo & 42 & 13,93 & 3,44 & 26,19 & 1494,92 \\
Média & & 18,12 & 14,42 & 6,87 & 23,95 \\
CV (\%) & & &
\end{tabular}

${ }^{n s}$ não significativo; ${ }^{* *}$ significativo para $\mathrm{P} \leq 0,01$; ${ }^{*}$ Significativo para $\mathrm{P} \leq 0,05$ pelo teste $\mathrm{F}$.

TABELA 3: Médias da característica massa de matéria seca da parte aérea, de três cultivares de feijão comum cultivadas em ambientes com diferentes épocas de adubação nitrogenada. Gurupi - Tocantins, 2012.

\begin{tabular}{lcccccc}
\hline \multirow{2}{*}{ Cultivares } & \multicolumn{6}{c}{ Massa de matéria seca da parte aérea (g.planta ${ }^{-1}$ ) } \\
\cline { 2 - 7 } & $\mathbf{E}_{\mathbf{1}}$ & $\mathbf{E}_{\mathbf{2}}$ & $\mathbf{E}_{\mathbf{3}}$ & $\mathbf{E}_{\mathbf{4}}$ & $\mathbf{E}_{\mathbf{5}}$ & Média \\
\cline { 2 - 7 } & $13,62 \mathrm{aA}$ & $8,50 \mathrm{aA}$ & $9,50 \mathrm{aA}$ & $9,00 \mathrm{aA}$ & $13,00 \mathrm{aA}$ & 10,72 \\
IPR Juriti & $9,50 \mathrm{abA}$ & $13,00 \mathrm{aA}$ & $11,62 \mathrm{aA}$ & $12,50 \mathrm{aA}$ & $13,65 \mathrm{aA}$ & 12,05 \\
IAC Alvorada & $6,50 \mathrm{bA}$ & $10,37 \mathrm{aA}$ & $7,00 \mathrm{aA}$ & $10,32 \mathrm{aA}$ & $10,75 \mathrm{aA}$ & 8,99 \\
BRS Requinte & 9,87 & 10,62 & 9,37 & 10,60 & 12,46 & \\
\hline Médias & &
\end{tabular}

Médias seguidas por diferentes letras minúsculas (coluna) e maiúsculas (linhas) diferem entre si pelo teste de Tukey a $5 \%$ de probabilidade. ${ }^{1} \mathrm{E}_{1}=$ Zero de $\mathrm{N} ; \mathrm{E}_{2}=100 \%$ de $\mathrm{N}$ aplicado na semeadura; $\mathrm{E}_{3}=100 \%$ de $\mathrm{N}$ aplicado aos $25 \mathrm{DAE} ; \mathrm{E}_{4}=50 \%$ de $\mathrm{N}$ aplicado aos 20 e $50 \%$ aos 30 DAE; $\mathrm{E}_{5}=33 \%$ de $\mathrm{N}$ aplicado aos $15,33 \%$ aos 25 e $33 \%$ aos 35 DAE. DAE = Dias após emergência. 
Quanto ao teor de nitrogênio nas folhas (Tabela 4), não foi verificado diferença entre os cultivares, bem como, entre as épocas de aplicação de nitrogênio.

De acordo com Malavolta et al. (1997), os valores encontrados são considerados adequados para a cultura (3 a 5 dag. $\left.\mathrm{kg}^{-1}\right)$, exceto para IAC Alvorada na testemunha e IPR Juriti com aplicação total de N na semeadura, mesmo assim, sendo muito próximos do adequado (2,95 dag. $\mathrm{kg}^{-1}$ ), evidenciado que as exigências mínimas das plantas em nitrogênio foram supridas em todos os tratamentos.

Apesar de Carvalho et al. (2001) ter observado a necessidade do $\mathrm{N}$ para o crescimento inicial do feijoeiro, segundo Hungria et al. (1985), do total de N requerido pelo feijoeiro durante o ciclo, apenas $31 \%$ é absorvido até o florescimento. Dessa forma, os resultados demonstram que o nitrogênio proveniente da fixação biológica (FBN) ou da mineralização da matéria orgânica do solo pode ter sido suficiente para manter a cultura bem nutrida até o florescimento, quando foram efetuadas as avaliações.
De acordo com Vargas et al. (2004), além da soja (Glycine max (L) Merryll), que é considerada como o mais notável exemplo de fixação de $\mathrm{N}_{2}$, sendo cultivada em milhões de hectares sem o uso de adubos nitrogenados, dentre outras leguminosas o feijoeiro apresenta grande potencial para fixação de $\mathrm{N}_{2}$ por estirpes nativas de rizóbio presentes no solo, podendo suprir a demanda da cultura por esse elemento. Hungria et al. (1997) evidenciaram ainda, estimativas que a fixação contribua, em média, com cerca de $50 \mathrm{~kg} \cdot \mathrm{ha}^{-1}$ de $\mathrm{N}$ para a cultura do feijoeiro, sendo que a resposta varia principalmente conforme as cultivares e estirpes de rizóbio presentes no solo.

Os resultados obtidos para característica massa de matéria seca da parte aérea podem ser explicados pelos teores de $\mathrm{N}$ nas folhas serem adequados para a cultura, mesmo no tratamento testemunha.

Para a característica altura de planta (Tabela 5), verifica-se que o cultivar IAC Alvorada apresentou maior

TABELA 4: Médias da característica teor de nitrogênio foliar, de três cultivares de feijão comum cultivadas em ambientes com diferentes épocas de adubação nitrogenada. Gurupi - Tocantins, 2012.

\begin{tabular}{|c|c|c|c|c|c|c|}
\hline \multirow{3}{*}{ Cultivares } & \multicolumn{6}{|c|}{ Teor de nitrogênio foliar (dag.kg-1) } \\
\hline & \multicolumn{6}{|c|}{ Época de aplicação de nitrogênio $^{1}$} \\
\hline & $E_{1}$ & $\mathbf{E}_{2}$ & $\mathbf{E}_{3}$ & $\mathbf{E}_{4}$ & $\mathbf{E}_{5}$ & Média \\
\hline IPR Juriti & 3,30 & 2,95 & 3,39 & 3,58 & 3,56 & $3,36 \mathrm{a}$ \\
\hline IAC Alvorada & 2,95 & 3,95 & 3,13 & 3,35 & 3,66 & $3,41 \mathrm{a}$ \\
\hline BRS Requinte & 3,48 & 3,31 & 3,24 & 3,11 & 3,19 & $3,27 \mathrm{a}$ \\
\hline Médias & $3,24 \mathrm{~A}$ & $3,40 \mathrm{~A}$ & $3,26 \mathrm{~A}$ & $3,34 \mathrm{~A}$ & $3,47 \mathrm{~A}$ & \\
\hline
\end{tabular}

Médias seguidas pela mesma letra minúscula (coluna) e maiúscula (linhas) não diferem entre si pelo teste de Tukey a 5\% de probabilidade. ${ }^{1} \mathrm{E}_{1}=$ Zero de $\mathrm{N} ; \mathrm{E}_{2}=100 \%$ de $\mathrm{N}$ aplicado na semeadura; $\mathrm{E}_{3}=100 \%$ de $\mathrm{N}$ aplicado aos $25 \mathrm{DAE} ; \mathrm{E}_{4}=50 \%$ de $\mathrm{N}$ aplicado aos 20 e $50 \%$ aos 30 DAE; $\mathrm{E}_{5}=33 \%$ de $\mathrm{N}$ aplicado aos $15,33 \%$ aos 25 e $33 \%$ aos 35 DAE. DAE = Dias após emergência.

TABELA 5: Médias da característica altura de planta, de três cultivares de feijão comum cultivadas em ambientes com diferentes épocas de adubação nitrogenada. Gurupi - Tocantins, 2012.

\begin{tabular}{lcccccc}
\hline \multirow{2}{*}{ Cultivares } & \multicolumn{5}{c}{ Altura de planta (cm) } \\
\cline { 2 - 7 } & $\mathbf{E}_{\mathbf{1}}$ & $\mathbf{E}_{\mathbf{2}}$ & $\mathbf{E}_{\mathbf{3}}$ & $\mathbf{E}_{\mathbf{4}}$ & $\mathbf{E}_{\mathbf{5}}$ & Média $^{\text {Época de aplicação de nitrogênio }} \mathbf{1}^{\mathbf{1}}$ \\
\cline { 2 - 7 } & 56,80 & 55,80 & 52,45 & 54,90 & 62,20 & $56,43 \mathrm{~b}$ \\
IPR Juriti & 77,30 & 85,40 & 90,60 & 82,90 & 76,46 & $82,53 \mathrm{a}$ \\
IAC Alvorada & 57,50 & 58,95 & 69,50 & 61,93 & 71,95 & $63,97 \mathrm{~b}$ \\
BRS Requinte & $63,86 \mathrm{~A}$ & $66,71 \mathrm{~A}$ & $70,85 \mathrm{~A}$ & $66,57 \mathrm{~A}$ & $70,20 \mathrm{~A}$ \\
\hline Médias & &
\end{tabular}

Médias seguidas por diferentes letras minúsculas (coluna) e maiúsculas (linhas) diferem entre si pelo teste de Tukey a 5\% de probabilidade. ${ }^{1} \mathrm{E}_{1}=$ Zero de $\mathrm{N} ; \mathrm{E}_{2}=100 \%$ de $\mathrm{N}$ aplicado na semeadura; $\mathrm{E}_{3}=100 \%$ de $\mathrm{N}$ aplicado aos $25 \mathrm{DAE} ; \mathrm{E}_{4}=50 \%$ de $\mathrm{N}$ aplicado aos 20 e $50 \%$ aos 30 DAE; $\mathrm{E}_{5}=33 \%$ de $\mathrm{N}$ aplicado aos $15,33 \%$ aos 25 e $33 \%$ aos 35 DAE. DAE = Dias após emergência. 
altura média quando comparado aos demais cultivares, e que não foi detectado diferenças entre as épocas de aplicação do nitrogênio. Todas os cultivares apresentaram estaturas superiores a $50 \mathrm{~cm}$, o que de acordo com HORN et al. (2000) é uma informação que demonstra o potencial destes genótipos para a colheita mecanizada. Resultados semelhantes foram observados por Santi et al. (2006) onde avaliando épocas e parcelamento da adubação nitrogenada no feijoeiro, obtiveram alturas de plantas superiores a $50 \mathrm{~cm}$. Da mesma forma, Salgado et al. (2012) avaliando 12 genótipos de feijão na região sul do Tocantins, observaram variação de 54,3 a $85,1 \mathrm{~cm}$ de altura sob condições de alta dose de nitrogênio (120 $\mathrm{kg} . \mathrm{ha}^{-1}$ de N). É importante destacar que normalmente plantas altas apresentam maior índice de acamamento, estando em relação à planta de menor porte propicia a maior ocorrência de tombamento causado pela ação de vento.

Quanto à inserção de primeira vagem (Tabela 6), observou-se que, de forma semelhante ao ocorrido em altura de plantas, maiores médias foram obtidas para IAC Alvorada independente da época de parcelamento do nitrogênio, apesar de não diferir significativamente do IPR Juriti na testemunha. Não houve diferença significativa entre as épocas de parcelamento para os cultivares IAC Alvorada e BRS Requinte. Para IPR Juriti, observou-se maiores médias para a testemunha e quando houve o parcelamento da dose de nitrogênio. Observa-se que, todos os cultivares obtiveram altura de inserção de primeira vagem superior a $15 \mathrm{~cm}$, estando aptas a colheita mecanizada.
Estes resultados corroboram com Santi et al. (2006) que avaliaram o efeito da adubação nitrogenada em feijoeiro e obtiveram médias de altura de inserção de primeira vagem acima de $21,75 \mathrm{~cm}$. Salgado et al. (2012) e Sousa et al. (2012) avaliando o efeito da adubação nitrogenada em feijoeiro no estado do Tocantins obtiveram, para esta característica, alturas que variaram entre 17,30 a 27,80 e 16,46 a 29,33 cm, porém, sem obter resposta diferenciada dos genótipos utilizados a adubação em condições de alto e baixo nível de $\mathrm{N}$, mostrando que essa característica provavelmente pode ter respostas variadas a adubação nitrogenada.

Silveira (1991) enfatiza que a prática da colheita mecanizada só é viável quando as vagens da base da planta se encontram a uma altura mínima de $15 \mathrm{~cm}$ acima da superfície do solo. Além do benefício da colheita mecanizada, a altura ideal evita o contato direto das vagens com o solo, impedindo o apodrecimento destas pelo excesso de umidade, promovendo assim melhor estado fitossanitário das sementes (SALGADO et al., 2012).

Quanto à característica diâmetro do caule (Tabela 7), observam-se maiores médias para IPR Juriti diferindo significativamente do IAC Alvorada apenas quando receberam nitrogênio parcelado aos 20 e 30 DAE. Menores médias foram observadas para BRS Requinte independente da época de parcelamento do nitrogênio, apesar de não diferir significativamente do cultivar BRS Alvorada quando recebeu parcelamento de nitrogênio aos 20 e 30 DAE e IPR Juriti quando recebeu todo o nitrogênio na semeadura.

TABELA 6: Médias da característica inserção de primeira vagem, de três cultivares de feijão comum cultivadas em ambientes com diferentes épocas de adubação nitrogenada. Gurupi - Tocantins, 2012.

\begin{tabular}{|c|c|c|c|c|c|c|}
\hline \multirow{3}{*}{ Cultivares } & \multicolumn{6}{|c|}{ Inserção da primeira vagem $(\mathrm{cm})$} \\
\hline & \multicolumn{6}{|c|}{ Época de aplicação de nitrogênio ${ }^{1}$} \\
\hline & $E_{1}$ & $\mathbf{E}_{2}$ & $\mathbf{E}_{3}$ & $\mathrm{E}_{4}$ & $\mathbf{E}_{5}$ & Média \\
\hline IPR Juriti & $20,80 \mathrm{aA}$ & $15,30 \mathrm{bB}$ & $16,35 \mathrm{bB}$ & $18,30 \mathrm{bAB}$ & $18,30 \mathrm{bAB}$ & 17,81 \\
\hline IAC Alvorada & $20,55 \mathrm{aA}$ & $20,40 \mathrm{aA}$ & $21,65 \mathrm{aA}$ & $21,20 \mathrm{aA}$ & $21,00 \mathrm{aA}$ & 20,96 \\
\hline BRS Requinte & $15,50 \mathrm{bA}$ & $16,25 \mathrm{bA}$ & $18,30 \mathrm{bA}$ & $15,40 \mathrm{cA}$ & $16,15 \mathrm{bA}$ & 16,32 \\
\hline Médias & 18,95 & 17,31 & 18,76 & 18,30 & 18,48 & \\
\hline
\end{tabular}

Médias seguidas por diferentes letras minúsculas (coluna) e maiúsculas (linhas) diferem entre si pelo teste de Tukey a 5\% de probabilidade. ${ }^{1} \mathrm{E}_{1}=$ Zero de $\mathrm{N} ; \mathrm{E}_{2}=100 \%$ de $\mathrm{N}$ aplicado na semeadura; $\mathrm{E}_{3}=100 \%$ de $\mathrm{N}$ aplicado aos $25 \mathrm{DAE} ; \mathrm{E}_{4}=50 \%$ de $\mathrm{N}$ aplicado aos 20 e $50 \%$ aos 30 DAE; $E_{5}=33 \%$ de $\mathrm{N}$ aplicado aos $15,33 \%$ aos 25 e $33 \%$ aos 35 DAE. DAE = Dias após emergência. 
Não houve diferença significativa entre as épocas de parcelamento para BRS Requinte. Para IPR Juriti observou-se menor média para testemunha, porém, sem diferir significativamente da utilização do nitrogênio na semeadura e quando parcelado aos 15, 25 e 35 DAE. IAC Alvorada apresentou menor média de diâmetro do caule quando houve parcelamento do nitrogênio aos 20 e 30 DAE, não diferindo significativamente da testemunha e do tratamento onde se aplicou todo o nitrogênio na semeadura.

Estes resultados contradizem os descritos por Salgado et al. (2012), onde não observou influência da adubação nitrogenada para esta característica nos genótipos avaliados quando utilizaram doses de 20 e 120 kg.ha ${ }^{-1}$. Segundo Coelho et al. (2007) esta característica é de pouca relevância para identificação de divergência genética. Porém, o diâmetro do caule apresenta função importante na sustentação da planta, de modo que, diâmetro maior evita índice elevado de acamamento, facilitando o processo de mecanização.

Quanto ao número de vagens por planta (Tabela 8), observa-se superioridade do cultivar IPR Juriti com 16,46 vagens, apesar de não diferir significativamente do IAC Alvorada com 14,82 vagens. Para época de aplicação de nitrogênio, observa-se maiores médias quando houve parcelamento do nitrogênio aos $15,25 \mathrm{e}$ 35 DAE com 15,16 vagens, diferindo significativamente apenas da testemunha com 12,20 vagens, demonstrando que a adubação nitrogenada proporciona melhor nutrição da planta e maior número de vagens por planta, com destaque para o parcelamento em três vezes.

TABELA 7: Médias da característica diâmetro do caule, de três cultivares de feijão comum cultivadas em ambientes com diferentes épocas de adubação nitrogenada. Gurupi - Tocantins, 2012.

\begin{tabular}{|c|c|c|c|c|c|c|}
\hline \multirow{3}{*}{ Cultivares } & \multicolumn{6}{|c|}{ Diâmetro do caule (mm) } \\
\hline & \multicolumn{6}{|c|}{ Época de aplicação de nitrogênio ${ }^{1}$} \\
\hline & $\mathbf{E}_{1}$ & $\mathbf{E}_{2}$ & $\mathrm{E}_{3}$ & $E_{4}$ & $\mathbf{E}_{5}$ & Média \\
\hline IPR Juriti & $5,15 \mathrm{aB}$ & $5,41 \mathrm{abAB}$ & $6,12 \mathrm{aA}$ & $6,26 \mathrm{aA}$ & $6,04 \mathrm{aAB}$ & 5,79 \\
\hline IAC Alvorada & $5,12 \mathrm{aAB}$ & $5,69 \mathrm{aAB}$ & $5,79 \mathrm{aA}$ & $4,85 \mathrm{bB}$ & $6,00 \mathrm{aA}$ & 5,49 \\
\hline BRS Requinte & $4,20 \mathrm{bA}$ & $4,75 \mathrm{bA}$ & $4,40 \mathrm{bA}$ & $4,68 \mathrm{bA}$ & $5,06 \mathrm{bA}$ & 4,62 \\
\hline Médias & 4,82 & 5,28 & 5,44 & 5,26 & 5,70 & \\
\hline
\end{tabular}

Médias seguidas por diferentes letras minúsculas (coluna) e maiúsculas (linhas) diferem entre si pelo teste de Tukey a 5\% de probabilidade. ${ }^{1} \mathrm{E}_{1}=$ Zero de $\mathrm{N} ; \mathrm{E}_{2}=100 \%$ de $\mathrm{N}$ aplicado na semeadura; $\mathrm{E}_{3}=100 \%$ de $\mathrm{N}$ aplicado aos $25 \mathrm{DAE} ; \mathrm{E}_{4}=50 \%$ de $\mathrm{N}$ aplicado aos 20 e $50 \%$ aos 30 DAE; $\mathrm{E}_{5}=33 \%$ de $\mathrm{N}$ aplicado aos $15,33 \%$ aos 25 e $33 \%$ aos 35 DAE. DAE $=$ Dias após emergência.

TABELA 8: Médias da característica número de vagens por planta, de três cultivares de feijão comum cultivadas em ambientes com diferentes épocas de adubação nitrogenada. Gurupi - Tocantins, 2012.

\begin{tabular}{|c|c|c|c|c|c|c|}
\hline \multirow{3}{*}{ Cultivares } & \multicolumn{6}{|c|}{ Número de vagens por planta (un) } \\
\hline & \multicolumn{6}{|c|}{ Época de aplicação de nitrogênio $^{1}$} \\
\hline & $\mathbf{E}_{1}$ & $\mathbf{E}_{2}$ & $\mathbf{E}_{3}$ & $\mathbf{E}_{4}$ & $\mathbf{E}_{5}$ & Média \\
\hline IPR Juriti & 14,15 & 16,40 & 16,55 & 19,20 & 16,00 & $16,46 \mathrm{a}$ \\
\hline IAC Alvorada & 12,95 & 17,75 & 13,65 & 14,45 & 15,33 & $14,82 \mathrm{a}$ \\
\hline BRS Requinte & 9,50 & 9,40 & 9,20 & 10,40 & 14,15 & $10,53 \mathrm{~b}$ \\
\hline Médias & $12,20 \mathrm{~B}$ & $14,51 \mathrm{AB}$ & $13,13 \mathrm{AB}$ & $14,68 \mathrm{AB}$ & $15,16 \mathrm{~A}$ & \\
\hline
\end{tabular}

Médias seguidas por diferentes letras minúsculas (coluna) e maiúsculas (linhas) diferem entre si pelo teste de Tukey a 5\% de probabilidade. ${ }^{1} \mathrm{E}_{1}=$ Zero de $\mathrm{N} ; \mathrm{E}_{2}=100 \%$ de $\mathrm{N}$ aplicado na semeadura; $\mathrm{E}_{3}=100 \%$ de $\mathrm{N}$ aplicado aos $25 \mathrm{DAE} ; \mathrm{E}_{4}=50 \%$ de $\mathrm{N}$ aplicado aos 20 e $50 \%$ aos 30 DAE; $\mathrm{E}_{5}=33 \%$ de $\mathrm{N}$ aplicado aos $15,33 \%$ aos 25 e $33 \%$ aos 35 DAE. DAE $=$ Dias após emergência. 
Portes (1996) evidenciou que plantas de feijão bem nutridas produzem mais flores e, consequentemente, mais vagens por planta. Dessa forma, observa-se claramente que a adubação nitrogenada influenciou de forma positiva o número de vagens por planta. Estes resultados corroboram com os obtidos por Binotti et al. (2007) e Arf et al. (2011) que também verificaram no primeiro e terceiro ano de cultivo, respectivamente, efeito das épocas de aplicação de nitrogênio para esta característica, com menores valores médios para a testemunha.

Quanto ao número de grãos por vagens (Tabela 9), observa-se a formação de três grupos estatísticos para os cultivares avaliados, sendo que BRS Requinte apresentou melhor desempenho com 4,47 grãos por vagem, seguido de IPR Juriti com 3,24 grãos e IAC Alvorada com 2,62 grãos por vagem. Para épocas de aplicação de $\mathrm{N}$, verifica-se diferença significativa apenas entre quando se parcelou o nitrogênio em 20 e 30 DAE e testemunha, obtendo-se menor e maior número médio de grãos por vagens, respectivamente. Estes resultados confrontam com os encontrados por Soratto et al. (2003), Gomes Júnior et al. (2005), Meira et al. (2005) e Arf et al. (2011), onde esta característica não foi influenciada pelas diferentes épocas de adubação nitrogenada, inclusive a testemunha na cultura do feijoeiro.

Segundo Andrade et al. (1998) a característica número de grãos por vagens é um caráter de alta herdabilidade genética, sendo portanto, pouco influenciada pelo ambiente. No entanto, Arf et al. (2004) estudando o manejo de $\mathrm{N}$ no cultivo de feijão, observaram que o número de sementes por vagem foi influenciado pelas doses de $\mathrm{N}$ aplicadas em cobertura, indicando que uma melhor nutrição em $\mathrm{N}$ pode aumentar o número de óvulos fertilizados por vagem, com os dados se ajustando a uma equação linear crescente. Didonet (2005) citou ainda que além do genótipo em utilização, esta característica depende de condições favoráveis à fertilização e fecundação do respectivo óvulo. Desta forma, como se esperava, esta característica sofreu pouca influência das épocas de aplicação de nitrogênio.

Com relação à massa de cem grãos (Tabela 10), verifica-se composição de dois grupos estatísticos para os cultivares, sendo que o cultivar IAC Alvorada apresentou maior média. Isto se deu provavelmente, devido a característica genética do próprio cultivar, que possui grãos maiores e consequentemente de maior massa. Como IAC Alvorada obteve menor número de grãos por vagens e por planta, os fotoassimilados foram distribuídos para uma menor quantidade de grãos (drenos), quando comparando com os demais cultivares, resultando em maior crescimento de massa das mesmas. Não foi detectada diferença significativa entre as épocas de aplicação do nitrogênio. Resultados semelhantes foram encontrados por Meira et al. (2005) e Arf et al. (2011) no segundo ano de cultivo, onde não observaram efeito significativo tanto das doses como das épocas de aplicação de nitrogênio em feijoeiro para esta característica.

TABELA 9: Médias da característica número de grãos por vagem, de três cultivares de feijão comum cultivadas em ambientes com diferentes épocas de adubação nitrogenada. Gurupi - Tocantins, 2012.

\begin{tabular}{lcccccc}
\hline \multirow{2}{*}{ Cultivares } & \multicolumn{7}{c}{ Número de grãos por vagem (un) $^{n}$} & \multicolumn{7}{c}{ Época de aplicação de nitrogênio $^{\mathbf{1}}$} \\
\cline { 2 - 7 } & $\mathbf{E}_{\mathbf{1}}$ & $\mathbf{E}_{\mathbf{2}}$ & $\mathbf{E}_{\mathbf{3}}$ & $\mathbf{E}_{\mathbf{4}}$ & $\mathbf{E}_{\mathbf{5}}$ & Média \\
\cline { 2 - 7 } & 3,34 & 3,52 & 2,74 & 2,65 & 3,96 & $3,24 \mathrm{~b}$ \\
IPR Juriti & 2,75 & 2,88 & 2,87 & 2,17 & 2,46 & $2,62 \mathrm{c}$ \\
BRC Alvorada & 4,84 & 4,42 & 4,41 & 4,33 & 4,34 & $4,47 \mathrm{a}$ \\
\hline Médias & $3,64 \mathrm{~A}$ & $3,60 \mathrm{AB}$ & $3,34 \mathrm{AB}$ & $3,05 \mathrm{~B}$ & $3,58 \mathrm{AB}$ \\
\hline
\end{tabular}

Médias seguidas por diferentes letras minúsculas (coluna) e maiúsculas (linhas) diferem entre si pelo teste de Tukey a 5\% de probabilidade. ${ }^{1} \mathrm{E}_{1}=$ Zero de $\mathrm{N} ; \mathrm{E}_{2}=100 \%$ de $\mathrm{N}$ aplicado na semeadura; $\mathrm{E}_{3}=100 \%$ de $\mathrm{N}$ aplicado aos $25 \mathrm{DAE} ; \mathrm{E}_{4}=50 \%$ de $\mathrm{N}$ aplicado aos 20 e 50\% aos 30 DAE; $\mathrm{E}_{5}=33 \%$ de $\mathrm{N}$ aplicado aos 15, 33\% aos 25 e 33\% aos 35 DAE. DAE = Dias após emergência 
Ferrão et al. (2001) propuseram que a proporção do crescimento da semente é intrínseca à cultivar, além de ter controle genético substancial. De acordo com Crusciol et al. (2001), citado por Soratto et al. (2006), a massa de 100 grãos é a característica que apresenta a menor variação percentual, em função das alterações no meio de cultivo. De modo que, em condições adversas, com restrição de $\mathrm{N}$, a planta de feijão preferencialmente formará poucos grãos nas vagens fixadas ao invés de vários e malformados, pois seu objetivo biológico é a perpetuação da espécie, concordando com os resultados obtidos neste trabalho.

Quanto à produtividade de grãos (Tabela 11), observa-se que o cultivar IAC Alvorada apresentou maior média, sem, portanto, diferir significativamente do IPR Juriti para todos os tratamentos, e diferindo do BRS Requinte apenas quando houve utilização de todo o nitrogênio na semeadura ou quando foi parcelado em 15, 25 e 35 DAE. Esta superioridade deu-se provavelmente pelo fato do IAC Alvorada apresentar maior massa de grãos, enquanto que, o IPR Juriti apresentou maior número de grãos e de vagens por planta, sem diferir significativamente de IAC Alvorada. Estes resultados comprovam os relatos feitos por Ferrão et al. (2001), onde enfatizaram que o rendimento de grãos do feijoeiro correlaciona-se principalmente com o número de vagens por área e massa da semente.

Não houve diferença significativa entre as épocas de aplicação do nitrogênio para o BRS Requinte. Para o IPR Juriti e IAC Alvorada, o tratamento onde houve parcelamento do $\mathrm{N}$ em três vezes, foi o único a diferir significativamente da testemunha e do tratamento onde se aplicou toda a dose aos $25 \mathrm{DAE}$, respectivamente.

TABELA 10: Médias da característica massa de 100 grãos, de três cultivares de feijão comum cultivadas em ambientes com diferentes épocas de adubação nitrogenada. Gurupi - Tocantins, 2012.

\begin{tabular}{lcccccc}
\hline \multirow{2}{*}{ Cultivares } & \multicolumn{5}{c}{ Massa de 100 grãos $(\mathbf{g})^{\text {Época de aplicação de nitrogênio }^{\mathbf{1}}}$} \\
\cline { 2 - 7 } & $\mathbf{E}_{\mathbf{1}}$ & $\mathbf{E}_{\mathbf{2}}$ & $\mathbf{E}_{\mathbf{3}}$ & $\mathbf{E}_{\mathbf{4}}$ & $\mathbf{E}_{\mathbf{5}}$ & Média \\
\cline { 2 - 7 } & 23,75 & 22,83 & 24,14 & 24,95 & 23,78 & $23,89 \mathrm{~b}$ \\
IPR Juriti & 33,17 & 32,64 & 30,27 & 30,25 & 32,63 & $31,79 \mathrm{a}$ \\
IAC Alvorada & 23,42 & 21,41 & 24,52 & 22,92 & 22,25 & $22,90 \mathrm{~b}$ \\
\hline BRS Requinte & $26,78 \mathrm{~A}$ & $25,62 \mathrm{~A}$ & $26,31 \mathrm{~A}$ & $26,04 \mathrm{~A}$ & $26,22 \mathrm{~A}$ \\
\hline
\end{tabular}

Médias seguidas por diferentes letras minúsculas (coluna) e maiúsculas (linhas) diferem entre si pelo teste de Tukey a $5 \%$ de probabilidade. ${ }^{1} \mathrm{E}_{1}=$ Zero de $\mathrm{N} ; \mathrm{E}_{2}=100 \%$ de $\mathrm{N}$ aplicado na semeadura; $\mathrm{E}_{3}=100 \%$ de $\mathrm{N}$ aplicado aos $25 \mathrm{DAE} ; \mathrm{E}_{4}=50 \%$ de $\mathrm{N}$ aplicado aos 20 e $50 \%$ aos 30 DAE; $\mathrm{E}_{5}=33 \%$ de $\mathrm{N}$ aplicado aos $15,33 \%$ aos 25 e $33 \%$ aos 35 DAE. DAE $=$ Dias após emergência.

TABELA 11: Médias da característica produtividade de grão, de três cultivares de feijão comum cultivadas em ambientes com diferentes épocas de adubação nitrogenada. Gurupi - Tocantins, 2012.

\begin{tabular}{lcccccc}
\hline \multirow{2}{*}{ Cultivares } & \multicolumn{5}{c}{ Produtividade de grão (kg.ha-1 $^{-1}$} \\
\cline { 2 - 7 } & $\mathbf{E}_{\mathbf{1}}$ & $\mathbf{E}_{\mathbf{2}}$ & $\mathbf{E}_{\mathbf{3}}$ & $\mathbf{E}_{\mathbf{4}}$ & $\mathbf{E}_{\mathbf{5}}$ & Média \\
\cline { 2 - 7 } & $1069 \mathrm{aB}$ & $1651 \mathrm{abAB}$ & $1313 \mathrm{aAB}$ & $1608 \mathrm{aAB}$ & $1868 \mathrm{aA}$ & 1502 \\
IPR Juriti & $1610 \mathrm{aAB}$ & $1838 \mathrm{aA}$ & $1081 \mathrm{aB}$ & $1355 \mathrm{aAB}$ & $1998 \mathrm{aA}$ & 1577 \\
IAC Alvorada & $1611 \mathrm{aA}$ & $1188 \mathrm{bA}$ & $1385 \mathrm{aA}$ & $1676 \mathrm{aA}$ & $1166 \mathrm{bA}$ & 1405 \\
BRS Requinte & 1430 & 1559 & 1260 & 1546 & 1677 \\
\hline Médias & & &
\end{tabular}

Médias seguidas por diferentes letras minúsculas (coluna) e maiúsculas (linhas) diferem entre si pelo teste de Tukey a 5\% de probabilidade. ${ }^{1} \mathrm{E}_{1}=$ Zero de $\mathrm{N} ; \mathrm{E}_{2}=100 \%$ de $\mathrm{N}$ aplicado na semeadura; $\mathrm{E}_{3}=100 \%$ de $\mathrm{N}$ aplicado aos $25 \mathrm{DAE} ; \mathrm{E}_{4}=50 \%$ de $\mathrm{N}$ aplicado aos 20 e $50 \%$ aos 30 DAE; $\mathrm{E}_{5}=33 \%$ de $\mathrm{N}$ aplicado aos $15,33 \%$ aos 25 e $33 \%$ aos 35 DAE. DAE = Dias após emergência. 
Mesmo com variações entre os cultivares, as produtividades foram consideradas satisfatórias independentes da época de aplicação de $\mathrm{N}$, quando comparadas à média nacional que é de 895 kg.ha-1 (CONAB, 2013). Esse efeito para IPR Juriti e IAC Alvorada foi devido, provavelmente, à maior disponibilidade do nutriente durante a fase de desenvolvimento e época do florescimento da cultura, que pode ter favorecido maior vingamento de vagens, resultando, assim, em maior número de vagens por planta e consequentemente maior produtividade.

Hungria et al. (1985) enfatizaram ainda que $60 \%$ do $\mathrm{N}$ mineral total acumulado pelo feijoeiro durante o ciclo é absorvido entre os estágios de florescimento e meados do estágio de enchimento dos grãos, explicando assim os melhores resultados do parcelamento do $\mathrm{N}$ em três vezes para IPR Juriti e IAC Alvorada. Os resultados obtidos no presente trabalho contradizem os encontrados por Soratto et al. (2003), que avaliaram cultivares de feijoeiro quanto ao parcelamento de nitrogênio, e mostraram que a aplicação de todo o nitrogênio em cobertura (22 DAE) proporcionou maior produtividade de grãos.

Já estudos realizados por Soratto et al. (2006) mostraram que a produtividade de grãos foi aumentada pela aplicação de $\mathrm{N}$ em cobertura, independente da forma de parcelamento utilizada em relação à testemunha. Contudo, existem controvérsias quanto à resposta da cultura a adubação nitrogenada na literatura, pois, Arf et al. (2011), utilizando $80 \mathrm{~kg} \cdot \mathrm{ha}^{-1}$ de $\mathrm{N}$, aplicados em diferentes parcelamentos, em dois anos de cultivos, obtiveram efeito significativo dos tratamentos em relação à testemunha apenas em um dos anos.

Segundo Rosolem (1996), a resposta do N está relacionada com o solo onde é implantada a cultura (cultura anterior, teor de matéria orgânica, textura do solo e irrigação). A resposta da cultura a aplicação de nitrogênio também pode ser influenciada por variações de clima e genótipo utilizado (CHIDI et al., 2002). É importante ressaltar que, a não diferenciação da testemunha em relação a alguns tratamentos se deu provavelmente, devido ao nitrogênio proveniente da fixação biológica $(\mathrm{FBN})$ ou da mineralização da matéria orgânica que liberaria quantidades suficientes de $\mathrm{N}$ para atender às necessidades da planta.
Desta forma, conclui-se que existe variabilidade genética entre os cultivares quanto à resposta, bem como, diferenças entre as épocas de adubação nitrogenada.

Os cultivares IAC Alvorada e IPR Juriti obtiveram maiores produtividades de grãos.

A época de aplicação de nitrogênio parcelada aos 15, 25 e 35 dias após a emergência, proporcionou maior produtividade de grãos para os cultivares IAC Alvorada e IPR Juriti.

\section{Referências}

AIDAR, H.; KLUTHCOUSKI, J. Manejo da adubação nitrogenada. In: KLUTHCOUSKI, J.; STONE, L. F.; AIDAR, H. (Ed.). Fundamentos para uma agricultura sustentável, com ênfase na cultura do feijoeiro. Santo Antônio de Goiás: Embrapa Arroz e Feijão, 2009. p. 269-277.

AMBrosAnO, E. J.; WUTKE, E. B.; AMBROSANO, G. M. B.; BULISANI, E. A.; BORTOLETTO, N.; MARTINS, A. L. M.; PEREIRA, J. C. V. N. A.; DE SORDI, G. Efeito do nitrogênio no cultivo de feijão irrigado no inverno. Scientia Agricola, Piracicaba, v. 53, n. 2-3, p. 338-341, 1996.

ANDRADE, M. J. B. de; DINIZ, A. C.; CARVALHO, J. G. de; LIMA, S. F. de. Resposta da cultura do feijoeiro à aplicação foliar de molibdênio e às adubações nitrogenadas de plantio e cobertura. Ciência e Agrotecnologia, Lavras, v. 22, n. 4, p. 499-508, 1998.

ARF, M. V.; BUZETTI, S.; ARF, O.; KAPPES, C.; FERREIRA, J. P.; GITTI, D. C.; YAMAMOTO, C. J. T. Fontes e épocas de aplicação de nitrogênio em feijoeiro de inverno sob sistema plantio direto. Pesquisa Agropecuária Tropical, Goiânia, v. 41, n. 3, p. 430-438, 2011.

ARF, O.; RODRIGUES, R. A. F.; SÁ, M. E.; BUZETTI, S.; NASCIMENTO, V. Manejo do solo, água e nitrogênio no cultivo de feijão. Pesquisa Agropecuária Brasileira, Brasília, v. 39, n. 39, p. 131-138, 2004.

BINOTTI, F. F. S.; ARF, O.; ROMANINI JÚNIOR, A.; FERNANDES, F. A.; SÁ, M. E.; BUZETTI, S. Manejo do solo e da adubação nitrogenada na cultura de feijão de inverno e irrigado. Bragantia, Campinas, v. 66, n. 1, p. 121-129, 2007.

BLUM, A. Plant breeding for stress environments. Boca Raton: CRC Press, 1988. 223 p.

BROUGHTON, W. J.; HERNÁNDEZ, G.; BLAIR, M.; BEEBE, S.; GEPTS, P.; VANDERLE YDEN, J. Beans (Phaseolus spp.) model food legumes. Plant and Soil, Dordrecht, v. 252, n. 1, p. 55-128, 2003.

CARDOSO, S. M.; SORATTO, R. P.; SILVA, A. H.; MENDONÇA, C. G. Fontes e parcelamento do nitrogênio em cobertura, na cultura do milho sob plantio direto. Revista Brasileira de Ciências Agrárias, Recife, v. 6, n. 1, p. 23-28, 2011.

CARVALHO, M. A. C.; ARF, O.; SÁ, M. E.; BUZETTI, S.; SANTOS, N. C. B.; BASSAN, D. A. Z. Produtividade e qualidade de sementes de feijoeiro (Phaseolus vulgaris L.) sob influência de 
parcelamento e fontes de nitrogênio. Revista Brasileira de Ciência do Solo, Viçosa, v. 25, n. 3, p. 617-624, 2001.

CHIDI, S. N.; SORATTO, R. P.; SILVA, T. R. B.; ARF, O.; SÁ, M. E.; BUZETTI, S. Nitrogênio via foliar e em cobertura em feijoeiro irrigado. Acta Scientiarum, Maringá, v. 24, n. 5, p. 1391-1395, 2002.

COELHO, C. M. M.; COIMBRA, J. L. M.; SOUZA, C. A.; BOGO, A.; GUIDOLIN, A. F. Diversidade genética em acessos de feijão (Phaseolus vulgaris L.). Ciência Rural, Santa Maria, v. 37, n. 5, p. 1241-1247, 2007.

CONAB. COMPANHIA NACIONAL DE ABASTECIMENTO. Acompanhamento da safra brasileira: grãos, sexto levantamento, março 2013. Brasília: CONAB, 2013. 36 p. Disponível em: < http://www.conab.gov.br/OlalaCMS/uploads/ arquivos/13_03_07_10_39_19_levantamento_safras_graos_6. pdf $>$. Acesso em: 24 mar. 2013.

CURI, S.; CAMPELO JÚNIOR, J. H. Necessidades hídricas da cultura do feijoeiro (Phaseolus vulgaris L.) na baixada cuiabana. Revista Brasileira de Agrometeorologia, Santa Maria, v. 9, n. 1, p. 59-65, 2001.

DIDONET. A. D. Ecofisiologia e rendimento potencial do feijoeiro. In: DEL PELOSO, M. J.; MELO, L. C (Ed.). Potencial de rendimento da cultura do feijoeiro. Santo Antônio de Goiás: Embrapa Arroz e Feijão, 2005. p. 9-37.

EMBRAPA. CENTRO NACIONAL DE PESQUISA DE SOLOS. Sistema Brasileiro de Classificação de Solos. 2. ed. Brasilia: EMBRAPA, 2006. 306 p.

FAGERIA, N. K.; BALIGAR, V. C. Enhancing nitrogen use efficiency in crop plants. Advances in Agronomy, Newark, v. 88, n. 1, p. 97-185, 2005.

FERRÃO, M. A. G.; VIEIRA, C.; CRUZ, C. D.; CARDOSO, A. A. Causas genéticas das correlações entre caracteres do feijoeiro avaliados no inverno. Revista Ceres, Viçosa, v. 48, n. 279, p. 573$582,2001$.

FERREIRA, D. F. SISVAR: a computer statistical analysis system. Ciência e Agrotecnologia, Lavras, v. 35, n. 6, p. 1039-1042, 2011. HORN, F. L.; SCHUCH, L. O. B.; SILVEIRA, E. P.; ANTUNES, I. F.; VIEIRA, J. C.; MARCHIORO, G.; MEDEIROS, D. F.; SCHWENGBER, J. E. Avaliação de espaçamentos e populações de plantas de feijão visando à colheita mecanizada direta. Pesquisa Agropecuária Brasileira, Brasília, v. 35, n. 1, p. 4146, 2000.

HUNGRIA, M.; NEVES, M. C. P.; VICTORIA, R. L. Assimilação do nitrogênio pelo feijoeiro. II. Absorção e translocação do $\mathrm{N}$ mineral e do N2 fixado. Revista Brasileira de Ciência do Solo, Campinas, v. 9, n. 1, p. 201-209, 1985.

HUNGRIA, M.; VARGAS, M. A. T.; ARAUJO, R. S. Fixação biológica de nitrogênio em feijoeiro. In: VARGAS, M. A. T.; HUNGRIA, M. (Ed.). Biologia dos solos dos cerrados. Planaltina: Embrapa-CPAC, 1997. p. 189-294.

GOMES JÚNIOR, F. G.; LIMA, E. R.; SÁ, M. E.; ARF, O.; RAPASSI, R. M. A. Rendimento do feijoeiro de inverno em resposta à época de semeadura e adubação nitrogenada em cobertura em diferentes estágios fenológicos. Acta Scientiarum, Maringá, v. 27, n. 1, p. 77-81, 2005.

LOPES, A. S.; WIETHOLTER, S.; GUILHERME, L. R. G.; SILVA, C. A. Sistema plantio direto: bases para o manejo de fertilidade do solo. São Paulo: Associação Nacional para Difusão de Adubos, 2004. $110 \mathrm{p}$.

MAlaVoltA, E.; VITTI, G. C.; OLIVEIRA, S. A. Avaliação do estado nutricional das plantas: princípios e aplicações. 2 ed. Piracicaba: Potafós, 1997. 319 p.

MEIRA, F. A.; SÁ, M. E.; BUZETTI, S.; ARF, O. Doses e épocas de aplicação de nitrogênio no feijoeiro irrigado cultivado em plantio direto. Pesquisa Agropecuária Brasileira, Brasília, v. 40, n. 4, p. 383-388, 2005.

PEEL, M. C.; FINLA YSON, B. L.; MCMAHON, T. A. Update world map of the Koppen-Geiger climate classification. Hydrology and Earth System Sciences, Göttingen v. 11, n. 5, p. 1633-1644, 2007.

PORTES, T. A. Ecofisiologia. In: ARAÚJO, R. S.; RAVA, C. A.; STONE, L. F.; ZIMMERMANN, M. J. O. (Coord.). Cultura do feijoeiro comum no Brasil. Piracicaba: Potafós, 1996. p. 101-137 ROSOLEM, C. A. Calagem e adubação mineral. In: ARAÚJO, R. S.; RAVA, C. A.; STONE, L. F.; ZIMMERMANN, M. J. de O. (Coord.). Cultura do feijoeiro comum no Brasil. Piracicaba: Potafós, 1996. p. 353-390.

SALGADO, F. H. M.; FIDELIS, R. R.; CARVALHO, G. L.; SANTOS, G. R.; CANCELLIER, E. L.; SILVA, G. F. Comportamento de genótipos de feijão, no período da entressafra, no sul do estado de Tocantins. Bioscience Journal, Uberlândia, v. 27, n. 1, p. 52-58, 2011.

SALGADO, F. H. M.; SILVA, J.; OLIVEIRA, T. C.; TONELLO, L. P.; PASSOS, N. G.; FIDELIS, R. R. Eeito do nitrogênio em feijão cultivado em terras altas no sul do estado de Tocantins. Ambiência, Guarapuava, v. 8, n. 1, p. 125-136, 2012.

SANT'ANA, E. V. P.; SANTOS, A. B.; SILVEIRA, P. Adubação nitrogenada na produtividade, leitura SPAD e teor de nitrogênio em folhas de feijoeiro. Pesquisa Agropecuária Tropical, Goiânia, v. 40, n. 4, p. 491-496, 2010.

SANTI, A. L.; DUTRA, L. M. C.; MARTIM, T. N.; BONADIMAN, R.; BELlÉ, G. L.; FLORA, L. P. D.; JAUER, A. Adubação nitrogenada na cultura do feijoeiro em plantio convencional. Ciência Rural, Santa Maria, v. 36, n. 4, p. 1079-1085, 2006.

SANTOS, J. B.; GAVILANES, M. L. Botânica. In: VIEIRA, C.; PAULA JÚNIOR, T. J.; BORÉM, A. (Ed.). Feijão. 2. ed. Viçosa: UFV, 2006. p. 41-65.

SILVEIRA, G. M. As máquinas para colheita e transporte. São Paulo: Globo, 1991. 184 p.

SODEK, L. Metabolismo do Nitrogênio. In: KERBAUY, G. B. (Ed.). Fisiologia Vegetal. 2. ed. Rio de Janeiro: Guanabara Koogan, 2008. p. 65-81.

SORATTO, R. P.; ARF, O.; RODRIGUES, R. A. F.; BUZETTI, S.; SILVA, T. R. B. Resposta do feijoeiro ao preparo do solo, manejo de água e parcelamento do nitrogênio. Acta Scientiarum, Maringá, v. 25, n. 1, p. 89-96, 2003.

SORATTO, R. P.; CRUSCIOL, C. A. C.; SILVA, L. M.; LEMOS, L. B. Parcelamento da adubação nitrogenada de cobertura no feijoeiro em sistema de plantio direto. Científica, Jaboticabal, v. 34, n. 2, p. 223-228, 2006.

SOUSA, S. A.; SILVA, J.; VENÂNCIO, J. L.; OLIVEIRA, T. C.; BARROS, H. B.; FIDELIS, R. R. Efeito do nitrogênio em genótipos de feijão cultivados em várzea úmida irrigada do Estado 
do Tocantins. Journal of Biotechnology and Biodiversity, Gurupi, v. 3, n. 2, p. 80-88, 2012.

VARGAS, M. A. T.; MENDES, L. C.; CARVAlHO, A. M.; BURLE, M. L; HUNGRIA, M. Inoculação de leguminosas e manejo de adubos verdes. In: SOUSA, D. M. G.; LOBATO, E. (Eds). Cerrado: correção do solo e adubação. 2 ed. Brasília: Embrapa Cerrados, 2004. p. 97-128.

VIEIRA, C. Adubação mineral e calagem. In: VIEIRA, C.; PAULA JÚNIOR, T. J.; BORÉM, A. (Ed.). Feijão. 2 ed. Viçosa: UFV, 2006. p. $115-142$.

VIEIRA, C.; PAULA JÚNIOR, T. J.; BORÉM, A. Feijão. 2 ed. Viçosa: UFV, 2006. 600 p. 